\title{
An implant to empty the bladder or close the urethra
}

\author{
G. S. BRINDLEY \\ From the MRC Neurological Prostheses Unit, Institute of Psychiatry, London
}

SU M M A R Y An implant has been designed which, in the baboon, will empty the bladder almost completely, or close the urethra so that urine does not leak out despite a contraction of the detrusor muscle. Electrodes on the 1st and 2nd sacral anterior nerve roots (corresponding roughly to the 3 rd and 4th sacral in man) suffice for both actions. Closing the urethra or emptying the bladder artificially in this way seems to cause conscious, neurologically intact, baboons no discomfort. Implants have remained in place for over two years, and have emptied the bladder artificially 12 times a day for many weeks, without deterioration of function.

Implanted stimulators now in use for the purpose of closing the urethra to treat incontinence (Caldwell et al., 1965; Alexander and Rowan, 1968; Riddle et al., 1969; Edwards and Malvern, 1972; Stanton and Edwards, 1973) stimulate at sites where sensory as well as motor nerve fibres are present. They have been moderately but not extremely successful. It seems fairly clear that they do not, at any stimulus strength that the patient can tolerate, stimulate all motor units of the striated closing muscles of the urethra. The evidence for this is that micturition is still possible during the strongest practically usable - that is, just notpainful-stimulation at 20 or $25 \mathrm{~Hz}$ through an implant (Alexander and Rowan, 1968; Caldwell, personal communication), although during prolonged maximal stimulation of the pudendal nerves at $24 \mathrm{~Hz}$, micturition is impossible in normal subjects, and this impossibility is not due to failure to initiate contractions of the detrusor muscle (Brindley et al., 1974).

Implants now in use for emptying the bladder employ electrodes either on the bladder wall (Bradley et al., 1962; Scott et al., 1965; Hald et al., 1967; Stenberg et al., 1967; Halverstadt and Parry, 1975; Merrill, 1975), or on the conus medullaris of the spinal cord (Nashold et al., 1972; Grimes and Nashold, 1974). The direct bladder-stimulating implants have been abandoned in many of the centres where they were originally tried. Merrill. who still uses them, reports (1976) that his overall success rate is $52 \%$ of 64 cases, and that patients with upper motor neurone lesions do worst, chiefly because the implant cannot remedy the detrusor-

Accepted 2 November 1976 sphincter dyssynergia which most such patients develop. Nashold's stimulator of the conus medullaris has yielded nine long-term successes among 12 patients (Nashold, 1976), but it also presumably cannot remedy detrusor-sphincter dyssynergia.

The present paper describes the completed animal experimental work on an implant that closes the urethra or empties the bladder, according to how it is used. It partly, and perhaps completely, avoids stimulation of pain nerve fibres; it does not require any structures in the spinal cord to be intact except anterior horn cells and their axons; and it can, in theory at least, overcome detrusorsphincter dyssynergia by ensuring that during the detrusor contraction the striated muscles are very fatigued. Brief preliminary reports of parts of the work have been published (Brindley 1972, 1973, 1974).

\section{Principle}

The preganglionic parasympathetic nerve fibres to the bladder and the somatic motor nerve fibres to the striated muscles that close the urethra are contained in the same ventral nerve roots, mainly $\mathbf{S 1}$ and $\mathrm{S} 2$ in the baboon, and S3 and S4 in man. Weak electrical stimuli delivered through electrodes permanently mounted on these roots will activate the striated closing muscles only, since the somatic motor nerve fibres are substantially larger, and, therefore, more electrically sensitive, than the parasympathetic. Strong electrical stimuli will activate the detrusor muscle of the bladder and the striated closing muscles. Since the smooth muscle relaxes much more slowly than striated muscle, if strong electrical stimuli are delivered in 
bursts with gaps of about two seconds between the bursts, the bladder will contract smoothly, but the striated closing muscles will relax during the gaps and allow urine to be expelled.

\section{Methods}

The form of implant now used is illustrated in Fig. 1. The part of the implant that lies within the spinal canal consists of a number of units called 'books'. Each 'book' has three or five thin silicone rubber 'pages', and the spinal nerve roots are inserted into the two or four slots between the pages. One or two books suffice for controlling the bladder and sphincters, but many baboons (see, for example, Fig. 2) have had more than two books implanted for other experimental purposes. Before October 1972 (Fig. 1 of Brindley, 1972), and since February 1975 (Fig. 1 of the present paper), each book has been connected to its neighbours by silicone rubber strips or cylinders. Some implants used in 1973 and 1974 consisted of two or more books unconnected to each other, but these proved to be less good because books sometimes rotated. Each book is connected to an extremely fatigue-resistant 4-conductor helical cable of a new design that will be described in detail elsewhere (Cooper, in preparation).

Surgery is done with full aseptic precautions. To insert an implant, laminectomy of the last three, four, or five lumbar vertebrae and the first piece of the sacrum is performed, the articular processes being carefully spared on one side but sacrificed on the other. Baboons usually have 12 thoracic and seven lumbar vertebrae, but in a minority the 'first lumbar' vertebra of the zoological textbooks is of thoracic form and bears ribs. In this paper, the last seven suprasacral segments will be called the first to seventh lumbar, whether or not the first of them has ribs. After laminectomy and removal of extradural fat, the dura mater is opened by a midline incision $60-90 \mathrm{~mm}$ in length and retracted, and the required nerve roots are identified by anatomical landmarks (which usually suffice), or by electrical stimulation. Dorsal and ventral roots can be distinguished from each other by sight at their places of exit through the dura mater almost as easily as at their place of origin from the spinal cord, although between these two places only electrical stimulation will allow them to be recognised. The roots to be inserted into the slots of the implant are looped with coloured thread and sep-

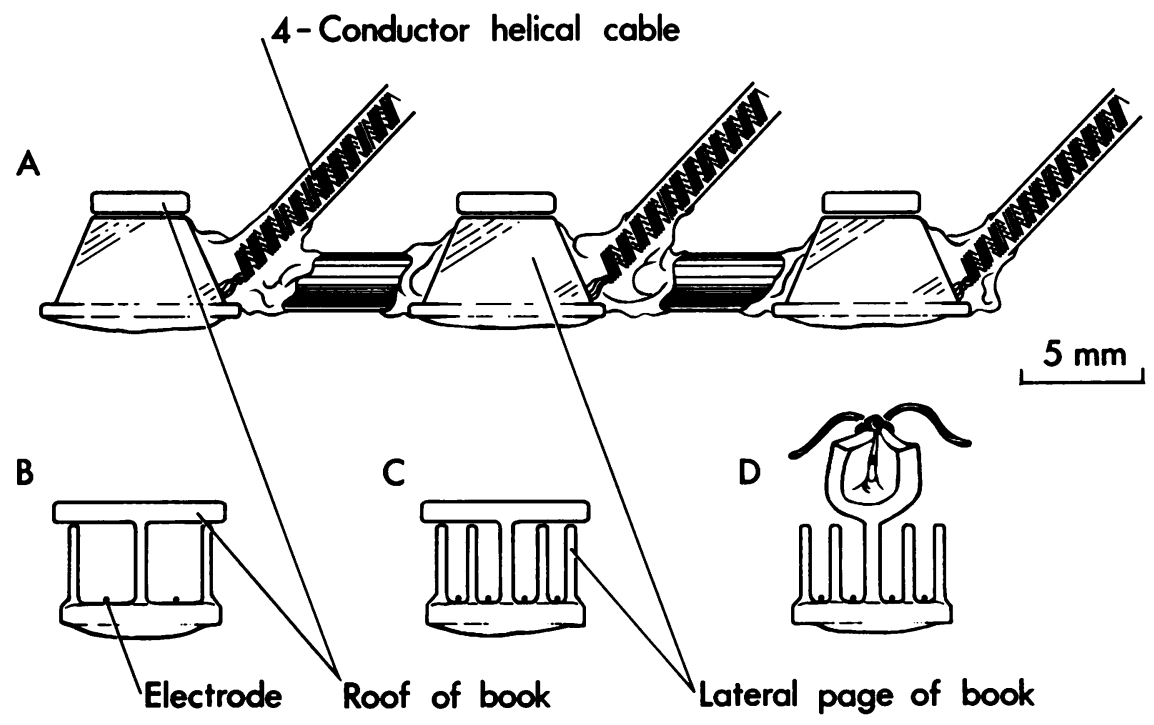

FIG. $1 A$. side view of a three-book implant. B. C. transverse sections through a threepage book and a five-page book with the roof down, as it is after implantation. D. a five-page book with roof tied up with a knotted thread in preparation for implantation; the roof is shown in perspective, and the pages and back in transverse section. Implants are made entirely of silicone rubber, except for the wires (the ends of which constitute the electrodes). These are of $90 \%$ platinum, $10 \%$ iridium, with an insulating layer of polyimide within the cable. 

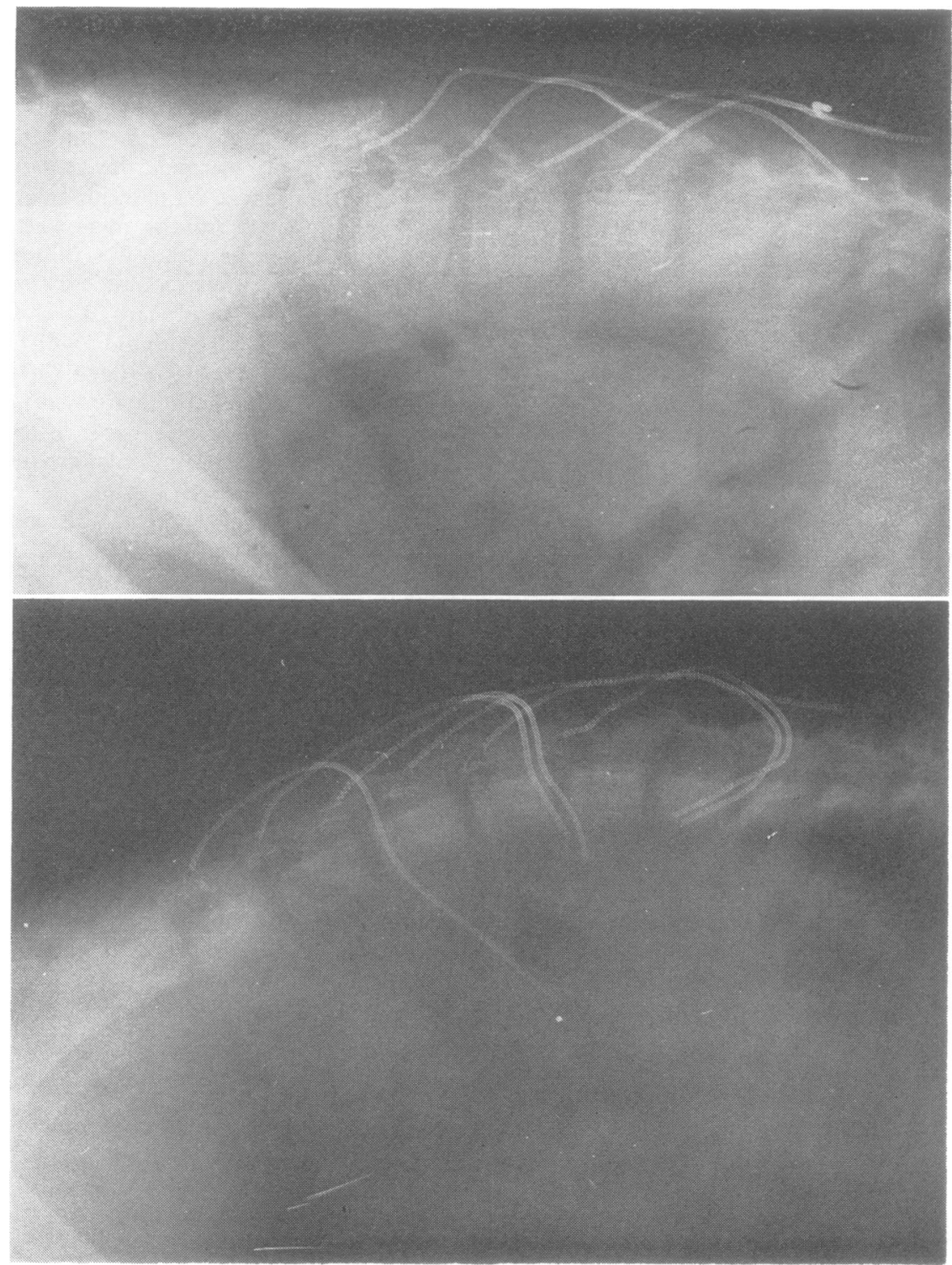

FIG. 2 Lateral X-ray photographs of a four-book implant immediately after implantation (B72), and a six-book implant six weeks after implantation (B76). Both animals are alive, and have now, 20 and 19 months respectively after implantation, a moderate kyphosis---that is, about twice as much as that seen in the six week picture of B76.

arated from the rest of the cauda equina as far up as necessary, fine strands of arachnoid mater that tether them being either torn, or cut with fine scissors. Often some roots are split in continuity, and strands put into separate slots. This procedure usually yields different kinds of movement from different strands of the same ventral root
(Brindley, 1973). When all the required roots and strands have been looped with thread and sufficiently dissected, the implant is lowered into the spinal canal, the roots and strands are placed in their slots, and the roofs of the slots are released by cutting their retaining threads (see Fig. 1D). The dura mater is left wide open. Two or three 
deep sutures are placed in the sacrospinalis muscle, chiefly to prevent backward displacement of the implant. The deep fascia is carefully sutured, and the cables from the implant laid out conveniently beneath the skin (which in the baboon is very loose). Then the skin is sutured.

Stimulation of roots can be done in three ways: by bringing the cables out through the skin and connecting them to an external stimulator, by connecting them aseptically to a subcutaneously placed passive radio receiving circuit, or by connecting them aseptically to a subcutaneously placed mutivibrator circuit with its own implanted battery. The first is practicable only under anaesthesia; the second and third permit stimulation in the unanaesthetised animal. For human application the second method will almost certainly be best, but for baboons, whose full cooperation is difficult to obtain, the third has great advantages.

\section{Results}

RESPONSE OF THE BLADDER TO SACRAL VENTRAL NERVE ROOT STIMULATION

In all of 26 baboons anaesthetised with pentobarbitone in which the $\mathbf{S 1}$ and/or $\mathbf{S} 2$ ventral nerve roots were stimulated while the pressure in the bladder was recorded, a rise in bladder pressure of between 25 and $104 \mathrm{mmHg}$ (usually between 40 and $60 \mathrm{mmHg}$ for optimal stimulation of left and right
$\mathrm{S} 1$ and $\mathbf{S} 2$ roots all together) was found. Some of these animals were tested several times, at intervals of weeks or months, always with similar results.

The pressure attained varied with the voltage of the stimulating pulses in the expected manner; that is, it increased with increasing voltage up to a limiting voltage ('maximal stimulus') at which presumably all parasympathetic fibres in the trapped root were being stimulated, and above this limit was independent of voltage. Maximal stimuli were used in most experiments, including all those for which records are published in the present paper. The duration of each stimulating pulse had little effect above $0.5 \mathrm{~ms}$; lowering the duration from $0.5 \mathrm{~ms}$ to $0.05 \mathrm{~ms}$ was roughly equivalent to halving the voltage. This conforms to expectation on the supposition that all the relevant nerve fibres stimulated are myelinated.

The highest peak pressures were reached with stimulating frequencies around 30 pulses/second, but fatigue increased with increasing frequency, so that the optimum frequency for maintaining a detrusor contraction for a minute or two may be 15 pulses/second or even less. Figure 3 illustrates the effect of frequency.

The volume of liquid in the bladder influences the pressure reached, but its influence is far smaller than has been argued by theorists from the assumption of constant tangential force per unit area of wall cross-section (implying $P \propto \mathrm{V}^{-1}$ ).

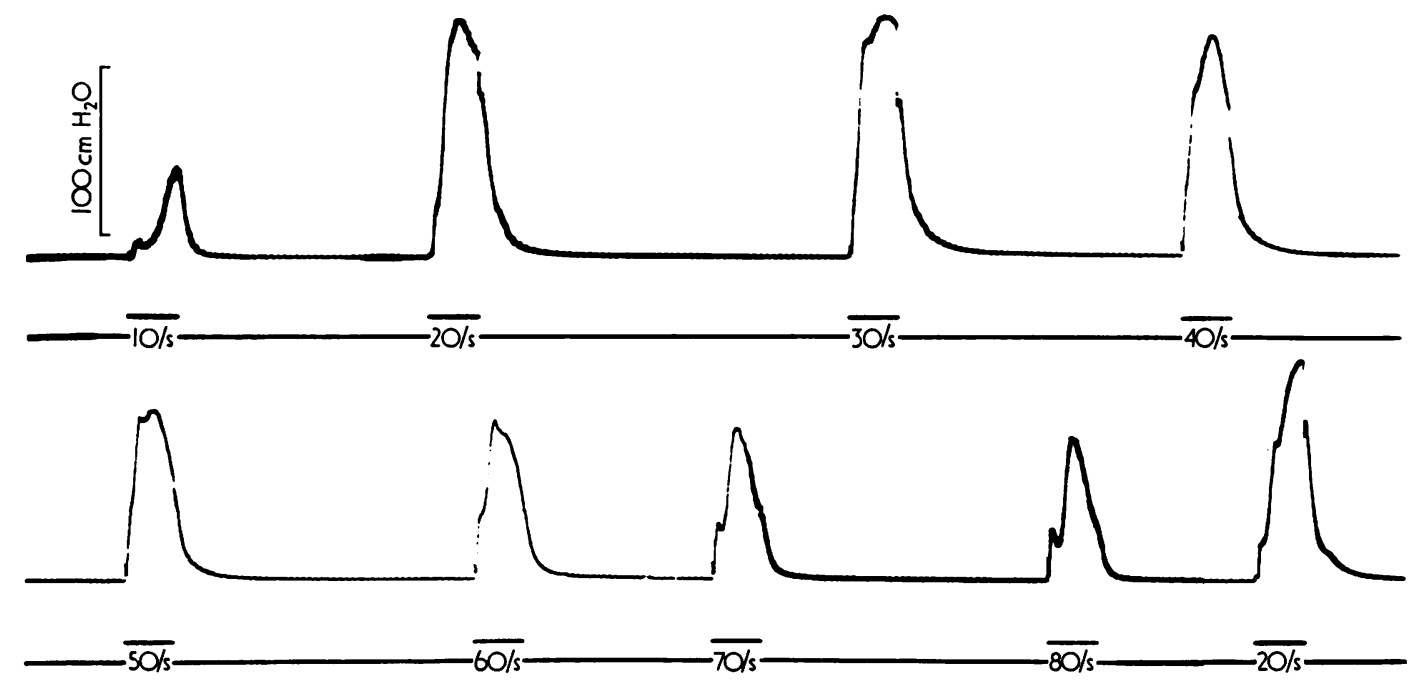

FIG. 3 Effect of frequency of stimulation of right and left $S 1$ and $S 2$ ventral roots all together on intravesical pressure, recorded by urethral catheter, in a male baboon (B72). Each period of stimulation lasted 20 seconds. Volume in bladder $15 \mathrm{ml}$. Implant had been in place for 12 months at time of experiment. 
Figure 4 illustrates the observed effect of volume. The fact that the pressure reached falls off with increasing volume far less steeply than as $P \propto V^{-1}$, up to $65 \mathrm{ml}$ volume (corresponding, weight for weight, to $600 \mathrm{ml}$ in an average man), shows that the bladder has a property analogous to Starling's law of the heart: it contracts with greater force per unit cross-sectional area if already stretched. Above $65 \mathrm{ml}$ volume (see the last three records) there is a much greater falling off of response with volume, and the relaxation when stimulation ceases becomes strikingly slow. I have no evidence at present to decide whether the slowing of relaxation is an intrinsic property of the bladder or depends on reflex activation of parasympathetic fibres. The final record of Fig. 4 was made 42 minutes after draining out the $105 \mathrm{ml}$, and shows that recovery from the presumable overstretching is still not complete in this time. The animal from which the records of Fig. 3 and Fig. 4 were made is typical in the features commented on above, but atypical in having the highest pressures under sacral root stimulation of the 26 baboons in which such pressures were measured.

The experiment illustrated in Fig. 5 shows that while the intravesical pressure response to stimulation of one pair of ventral roots is greatly modified by previous stimulation of the same pair, it is almost entirely unaffected by previous stimulation of a different pair, even though that stimulation caused a substantial rise in bladder pressure: there is little or no cross-fatigue.

Figure 6 illustrates that a substantially raised intravesical pressure can be sustained for $2 \mathrm{~min}$ $40 \mathrm{~s}$ by stimulating with the temporal pattern now used to produce artificial micturition. The details of this pattern were chosen chiefly on the basis of experiments like that of Fig. 6.

RESPONSE OF THE URETHRAL SMOOTH MUSCLE TO SACRAL VENTRAL NERVE ROOT STIMULATION

In the cat, Elliot (1907) showed that the urethral smooth muscle ('internal sphincter of the urethra') contracts under sympathetic nerve stimulation, relaxes under parasympathetic stimulation, and has tone in the anaesthetised animal which depends, at least in part, on impulses continually arriving along sympathetic fibres. Whether or not man resembles the cat in this has been the subject of much controversy. My observations on the

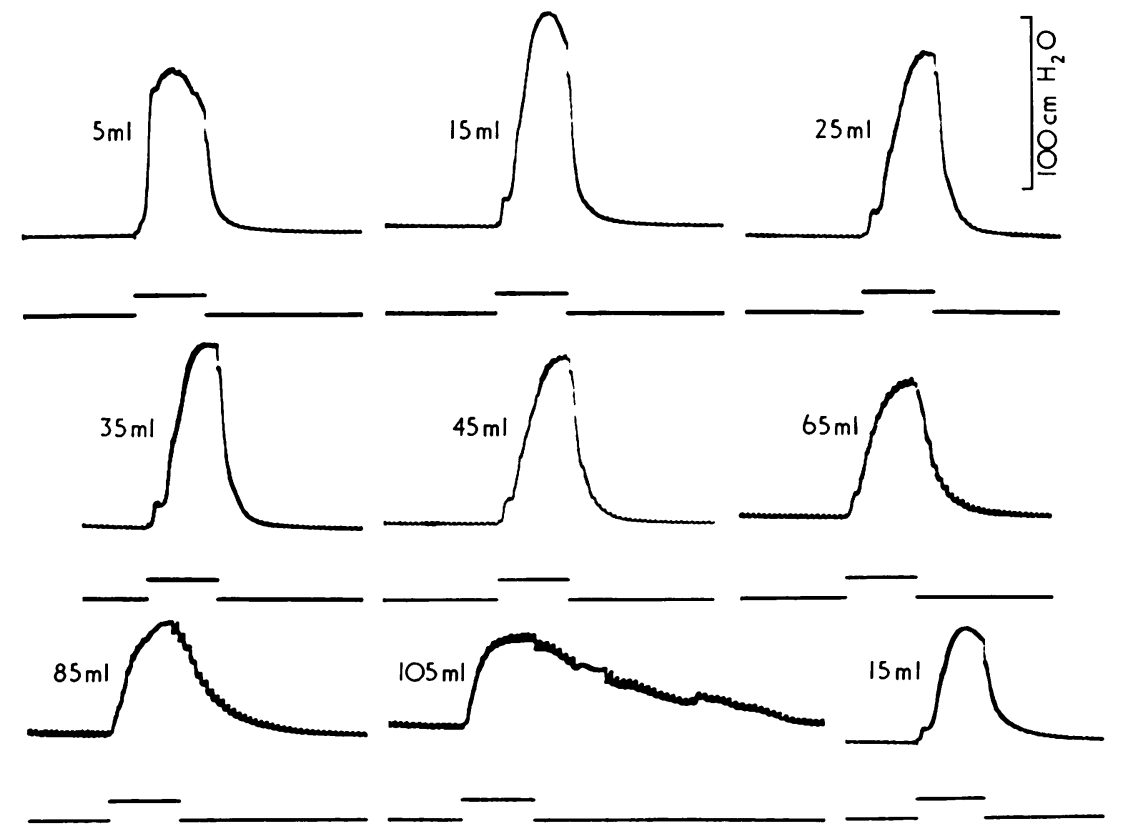

FIG. 4 Effect of volume in bladder on intravesical pressure responses to stimulating right and left $S 1$ and $S 2$ ventral roots, all together, at 20 pulses per second. Each period of stimulation lasted 30 seconds. The small ripples, greater at greater bladder volumes, represent respiratory fluctuations in abdominal pressure. A pause in breathing can be seen in the $105 \mathrm{ml}$ record. Male baboon (B72) weighing $7.6 \mathrm{~kg}$. 


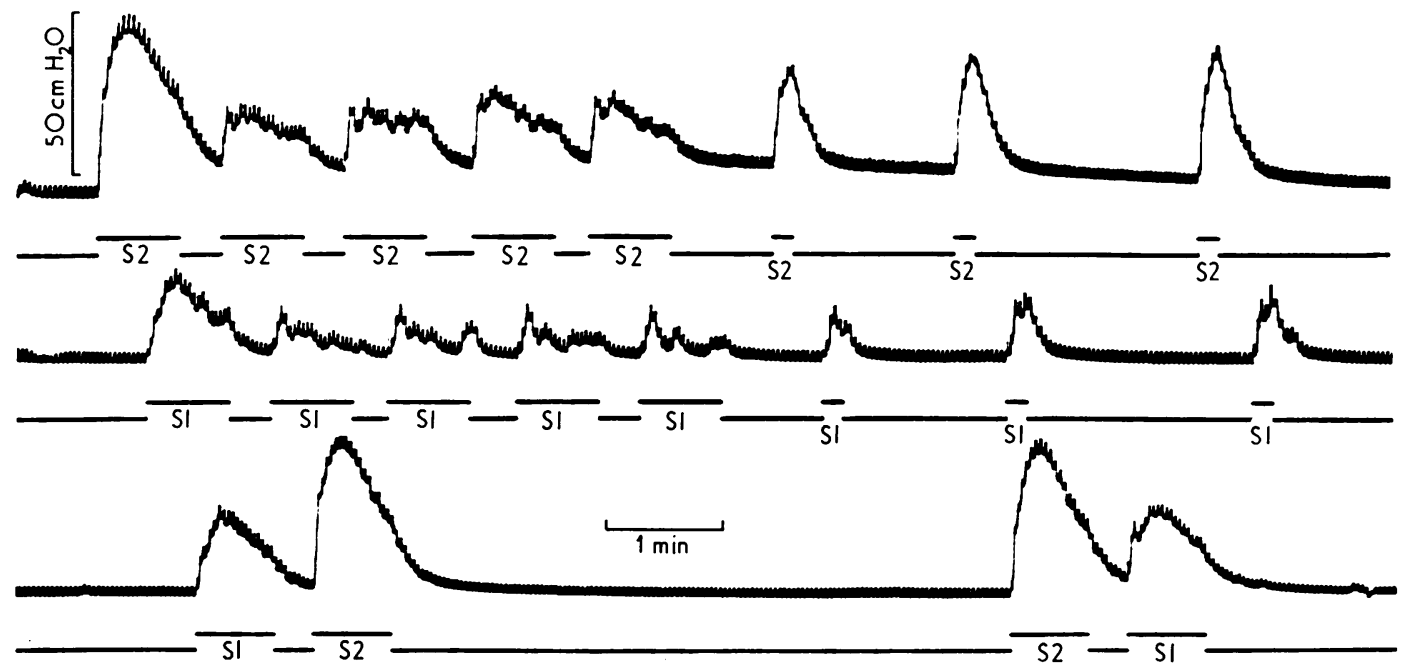

FIG. 5 Experiment to investigate self-fatigue and cross-fatigue between roots in causing intravesical pressure responses. Stimulation was at 80 pulses per second. During periods marked 'S1', both S1 roots were stimulated, and during periods marked 'S2' both $S 2$ roots. Male baboon (B76) weighing $7.9 \mathrm{~kg}$. Volume in bladder $50 \mathrm{ml}$. The ripples are respiratory. Implant had been in place for 11 months at time of experiment.

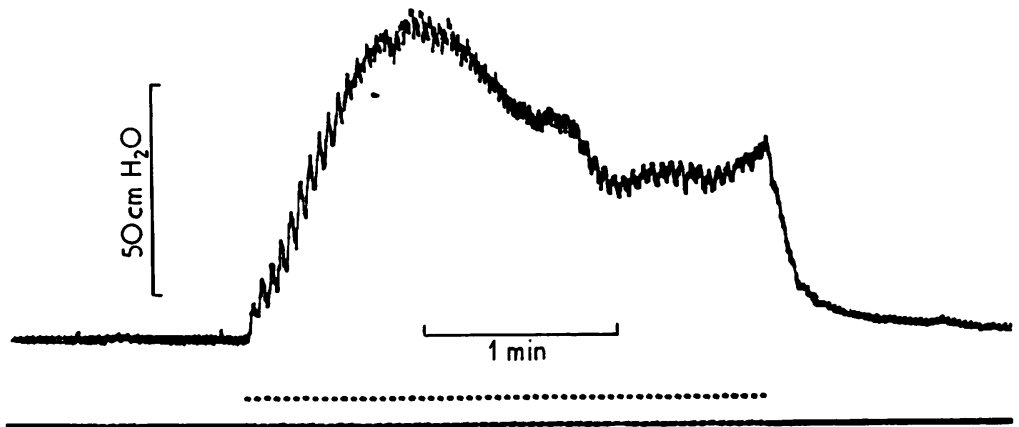

FIG. 6 Intravesical pressure response to pattern of stimulation now used to produce artificial micturition-that is, regular alternation of a train of 50 pulses lasting $1 \mathrm{~s}$ with a gap of $2 \mathrm{~s}$. Male baboon (B85) weighing $6.8 \mathrm{~kg}$. Volume in bladder $20 \mathrm{ml}$. The small ripples, best seen after the end of stimulation, are respiratory. The large ripples occurring during stimulation are probably mainly due to intermittent pelvic floor contractions.

baboon tend to indicate that the baboon does resemble the cat; but they are incomplete, and cannot be completed until the time comes for killing the nine baboons that now have implants. This work will, therefore, be reported separately later.

CLOSURE OF THE URETHRA BY SACRAL NERVE ROOT STIMULATION

In the experiment shown in Fig. 7, which was repeated on two other anaesthetised male baboons with similar results, a catheter was firmly tied into the penile urethra, and sterile water pumped into the initially empty bladder at $3 \mathrm{ml} /$ minute. The trace shows the catheter pressure, which is thus the pressure required to force the sphincteric region of the urethra open. For 30 second periods with pauses of about $50 \mathrm{~s}$ between them, the right and left S1 and S2 ventral nerve roots were stimulated all together at a voltage maximal for somatic motor nerve fibres but subliminal for detrusor 


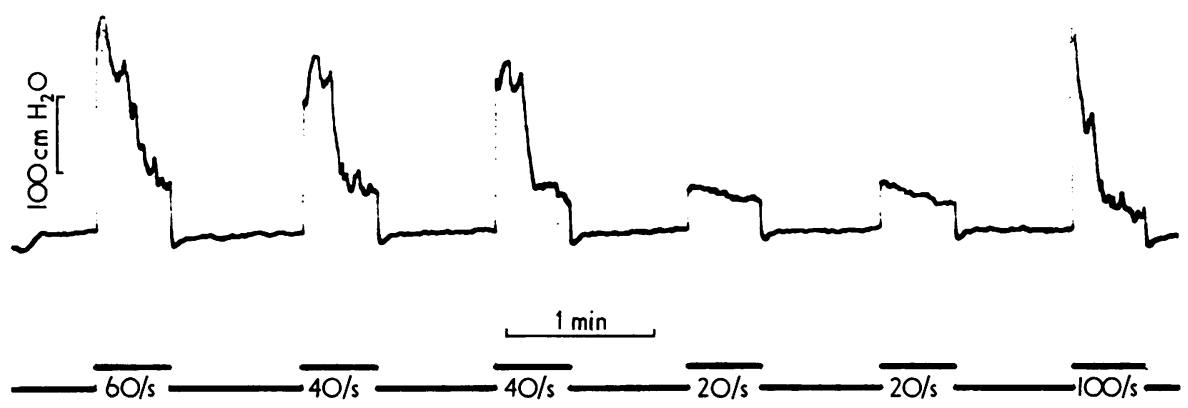

FIG. 7 Effect of stimulation of left and right $S 1$ and $S 2$ ventral roots together with shocks maximal for somatic motor nerve fibres but subliminal for parasympathetic fibres on urethral closure pressure. This was recorded as pressure at the external meatus required to force water past the sphincteric region into the bladder. Male baboon (B76).

contraction-a substantial range of such voltage always exists; presumably the baboon's largest sacral parasympathetic fibre is much smaller than its smallest sacral somatic motor fibre. The record shows that stimulation at 40,60 , or 100 pulses per second causes the urethral closure pressure to rise initially by more than $200 \mathrm{cmH}_{2} \mathrm{O}$, but the response fatigues greatly during 30 seconds. Stimulation at 20 pulses per second causes the urethral closure pressure to rise initially by only about $\mathbf{5 0}$ $\mathrm{cmH}_{2} \mathrm{O}$, but the fatigue is far less.

In four anaesthetised female baboons, continuous stimulation at $20 / \mathrm{s}$ at a voltage maximal for somatic nerve fibres but subliminal for bladder contractions was applied for three minutes, and the voltage then increased to that previously shown to give maximal bladder contractions. In three of them (B36, B57, and B58, the latter two with implants that had already been in place for over two years), no urine leaked out. The artificial micturition pattern (50 pulses in $1 \mathrm{~s}$ alternating with $2 \mathrm{~s}$ pause) was then applied and they immediately voided $45 \mathrm{ml}, 241 \mathrm{ml}$, and $62 \mathrm{ml}$ respectively. In the fourth (B86), $2 \mathrm{ml}$ of urine leaked when the voltage of $20 / \mathrm{s}$ stimulation was increased. The artificial micturition pattern then yielded $37 \mathrm{ml}$ more. Thus in three of these four baboons, the fatigued striated muscles sufficed for continence against a maximal bladder contraction, and in the fourth they seem to have been not very far from sufficient.

EMPTYING THE BLADDER BY SACRAL NERVE ROOT STIMULATION

The pattern of stimulation now used to empty the bladder is a train of 50 pulses occupying one second, alternating with a gap of two seconds. Each pulse lasts $100 \mu \mathrm{s}$, and its amplitude (typically about $40 \mathrm{~V}$ ) is adjusted until it just does not give movements attributable to spread of current to neighbouring nerve roots. In former years slightly different patterns were used (Brindley, 1973, 1974). The new pattern is a little, but only a little, more effective than the old.

Artificial micturition was produced in all animals in which it was attempted-that is, five recently paraplegic baboons (still in spinal shock), and 15 non-paraplegic. Paraplegic animals were tested without anaesthesia, non-paraplegic under pentobarbitone anaesthesia, except that one nonparaplegic female baboon (B55) and three nonparaplegic male baboons (B60, B72, and B85) had implanted multivibrators which, during several weeks, caused artificial micturition every two hours. I had no way of measuring the residual volumes left after the artificial micturitions produced by implanted multivibrator in the unanaesthetised state. In B55 (the female), firing of the multivibrator often caused a large volume of urine to be passed, and the bladder then seemed to be empty on the evidence that, immediately afterwards, close inspection by a stranger (ordinarily a powerful stimulus to micturition in baboons) provoked no micturition or only a few drops. In the three males, firing of the multivibrator caused penile erection and the passing of from a few drops to about $10 \mathrm{ml}$ of urine. The residual urine remaining after artificial micturition in them was sometimes demonstrably large, and by analogy with other males (see below) may always have been large.

All tests under anaesthesia in which the residual volume was measured are shown in Table 1 . The measurements were made by expressing the residual urine, or occasionally by the phenolsulphonphthalein (PSP) dilution test of Cotran and Krass 
Table 1 Volumes voided by sacral root stimulation, and the residual volumes left after such 'artificial micturition'

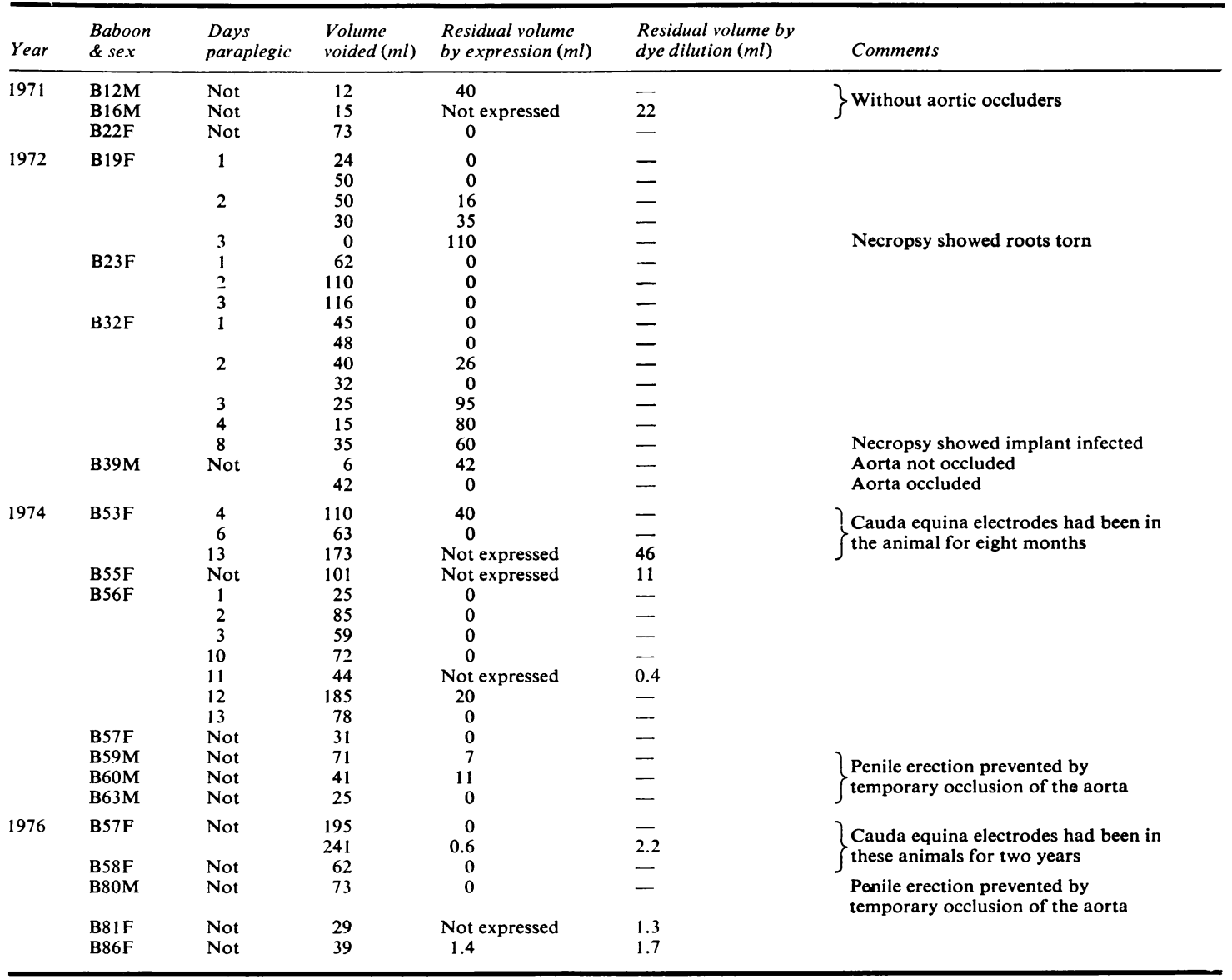

(1958), rendered more accurate by injecting the PSP into the bladder (B12, B55), or by increasing the interval between intravenous injection of PSP and first emptying the bladder to at least five hours (B.53, B56, B57, B81, B86). The efficacy of expression as a means of emptying the bladder of the anaesthetised baboon was measured by the Cotran and Kass test in three animals. Two of these (B57 and B86, both females) appear in Table 1; expression left 1.6 and $0.3 \mathrm{ml}$ respectively. In the third baboon (a male) it left $0.5 \mathrm{ml}$.

The main point illustrated by Table 1 is that appropriately patterned stimulation of the $S 1$ and S2 ventral nerve roots empties the bladder with a residual volume not exceeding $11 \mathrm{ml}$ and usually not exceeding $2 \mathrm{ml}$ except in three situations: (a) when the nerve roots are torn or infected (B19,
B32); (b) sometimes (B53, B56) but not always (B23, B57) when the volume voided exceeds 100 $\mathrm{ml}$; and (c) in male baboons in which penile erection occurs, as it always does on powerful $\mathrm{S} 1,2$ stimulation unless the blood supply to the penis is artificially obstructed. Of the male baboons, B39 had, in its terminal experiment, temporary provision for occluding its aorta, and B59, 60, 63, and 80 had aortic occluding implants (Brindley, 1974). When, by these means, the aorta was occluded during patterned $\mathrm{S} 1,2$ stimulation, the bladder emptied well; when the aorta was not occluded, it emptied poorly.

SURGICAL FAULTS AND MISFORTUNES

The following harmful effects of insertion of cauda equina implants were observed. 
Kyphosis

Fifty-nine baboons were kept alive for more than a month after laminectomy. Ordinarily this was of the last four lumbar vertebrae and the sacrum, but in 10 of the 59 the sacrum was not included in the laminectomy, and in three of them five lumbar vertebrae were included. About three-quarters of the baboons developed some lumbar kyphosis, usually slight. It was severe in six animals. Its effect on breathing may have predisposed to the pneumonia from which one of these six died, and its mechanical effect on the implant was probably the cause of late damage to the right L5 root in one other (B44; see below). With these exceptions the kyphosis, even when severe, seemed to cause the animals no inconvenience.

\section{Damage to nerve roots apparently occurring at or} immediately after implantation

The implants were designed primarily for ventral nerve roots, and the slots were made so that no ventral root was a tight fit in its slot. However, dorsal roots (which are about twice as large as ventral) were fairly often inserted into slots in which they fitted tightly. Many of these dorsal roots were found to be inexcitable, and it seems likely that they failed from ischaemia very soon after implantation.

In two baboons operated on in 1970 , ventral roots were split in continuity into four or five strands, and some of the smaller of these strands were subsequently found to be inexcitable. In later years, 46 ventral roots in 11 baboons have been split in continuity, each into two, three, or occasionally four approximately equal strands. Of 118 such strands subsequently tested, only five have been found to be inexcitable.

Three baboons (B35, B37, and B38) received in 1972 implants more ambitious (in terms of number of slots) than any earlier ones. These three animals had weakness of both legs on the day after operation, and subsequently showed wasting, chiefly of L4-5 myotome distribution. Subsequently, as my technique improved, even more ambitious implants (B46, B72, B76) were inserted without damage to roots.

Damage to nerve roots probably occurring between one day and two weeks after implantation

In one paraplegic female baboon (B32) in which a radio receiver had been implanted subcutaneously so that the S1 and S2 nerve roots could be stimulated at will without anaesthetic, the roots were found to be functioning well on the first two days after implantation, but poorly on the third, fourth, and eighth days. The animal was killed on the ninth day, and pus around the implant and cauda equina was found at necropsy. This was the only animal in which serious infection of a cauda equina implant occurred.

In one baboon certainly (B19, on necropsy evi- $D$ dence), and in two probably (B63 and B64, on radiological evidence), early failure of the $\mathrm{S} 1$ and S2 roots can be attributed to backward displace- $\vec{z}$ ment of the implant, which stretched or broke the roots. The operation has now been modified so $\stackrel{5}{9}$ that this is unlikely to happen again. The damaged roots in B63 and B64 subsequently regenerated.

\section{Late damage to nerve roots}

This occurred only in B44. This baboon was killed 25 months after insertion of an implant which $\vec{\circ}$ trapped, on the right side only, the fifth lumbar ventral nerve root unsplit, the seventh lumbar $\vec{\omega}$ dorsal root unsplit, the sixth lumbar ventral root split into three strands, and the sixth lumbar dorsal root and the seventh lumbar ventral root each split into two strands. All roots and strands. were excitable at five weeks, and there was no wasting at four, 12 , or 15 months, but at 23 mont moderate wasting of the right quadriceps musctit (innervated chiefly by L 5 nerve root in the baboog? was noticed. At necropsy it was found that the part of the implant in which the fifth lumbsy응 ventral root was trapped had rotated, probably a result of the slowly increasing spinal deformits The damage to the right L.5 root was not complete, for electrical stimulation of it at 25 months caused extension of the knee. Histological examination showed roughly three-quarters of the nerve fibres of this root to be replaced by fibrous tissue. All the other trapped roots and strands in B44 looked $\mathbb{D}$ histologically normal, though embedded in dense $\overline{\bar{B}}$ fibrous tissue.

\section{Leakage of cerebrospinal fluid}

Accumulation of fluid under the skin around the incision could of ten be seen on the day after the operation. The baboons were rarely handled until 0 the skin sutures were removed, on or about the seventh day. By then the incision was always $\delta$ healed, and the fluid had almost disappeared; in $₹$ the very few cases where there was still subcutane- 0 ous fluid on the seventh day, it had gone by the 14 th.

At necropsy several months after implantation, the lumbo-sacral subarachnoid space around the os implant was usually found to be obliterated. In a N few cases some subarachnoid space was found, but $N_{\omega}$ it was always smaller than normal. 
OBSERVATIONS RELEVANT TO THE SAFETY OF TRAPPING NERVE ROOTS FOR A LONG TIME AND STIMULATING THEM ELECTRICALLY

Table 2 assembles information about the 10 baboons that have had electrodes implanted on ventral roots for 12 months or more. Only one (B44, described above) showed late wasting of the muscles innervated by any trapped root. Every ventral root or strand of a split ventral root that was inserted into a slot in a book was found to be excitable on the last occasion of testing in B64 and B76, and on all occasions of testing in all other animals. B76 is especially informative. Its right L7 ventral root, on which two pairs of electrodes had been implanted in July 1975, was destroyed electrolytically on 26 November 1975 , and its inexcitability verified on 15 December 1975. On 10 March 1976 it was re-tested. Stimulation of the right L7 root through either of its pairs of electrodes yielded the same movement as before the electrolytic destruction, matching closely the movement obtained from the left L7 root. The threshold for the right root was $60 \%$ higher, and for the left $10 \%$ higher, than in September 1975. A further test in September 1976 showed that the threshold for the right L7 root had returned to within $10 \%$ of its September 1975 value. It is already known (Cajal, 1928) that ventral nerve roots regenerate if damaged; the importance of the observations on B76 is that the same movement was obtained after regeneration as before destructionthat is, that most of the regenerated fibres run near enough to their original courses to be accessible to stimulation through the implanted electrodes.

In the two longest-surviving animals, B57 and B58, the movements obtained from stimulation of the trapped nerve roots did not change, and the thresholds for obtaining them did not change by more than $10 \%$, between the second and the 30 th month after implantation.

Seven baboons have had the $\mathbf{S 1}$ and $\mathbf{S} 2$ anterior roots stimulated by internally powered implanted multivibrators with blocking capacitors in the outputs. In two of these (B42 for 28 days and B50 for 15 days), the stimuli were just sufficient to give maximal somatic motor responses, and were delivered at 20 or 66 pulses/s, a minute of stimulation alternating with a minute's pause. In the other five (B53F for 14 days, B55F for 49 days, B60M for 105 days, B72M for 33 days, and B85M for 23 days), the stimuli were sufficient to give parasympathetic effects (micturition in the two females, erection and incomplete micturition in the three males), and were delivered as 30-pulse bursts every $1.6 \mathrm{~s}$ for four minutes, each four minute period of stimulation alternating with a pause of 1 hour 56 minutes, so that stimulation occurred every two hours, day and night. In all six animals the effects of stimulation were the same, and the thresholds for producing them very nearly the same, after the long-term stimulation as before.

DOES STIMULATION OF SACRAL ANTERIOR NERVE ROOTS CAUSE PAIN?

The observations of Coggeshall et al. (1975) that

Table 2 Baboons with ventral roots trapped for 12 months or more

\begin{tabular}{|c|c|c|c|c|}
\hline $\begin{array}{l}\text { Year } \\
\text { of laminectomy }\end{array}$ & Baboon & $\begin{array}{l}\text { Survival } \\
\text { (months) }\end{array}$ & Roots trapped & Other information \\
\hline 1970 & $\begin{array}{l}\text { B5 } \\
\text { B13 }\end{array}$ & $\begin{array}{l}12 \\
20\end{array}$ & $\begin{array}{l}6 \text { ventral, } 4 \text { dorsal } \\
6 \text { ventral (L5 to } L 7) \text {, } \\
\text { two of them split }\end{array}$ & $\begin{array}{l}\text { No wasting, despite severe kyphosis } \\
\text { No wasting }\end{array}$ \\
\hline 1971 & $\mathbf{B 2 0}$ & 21 & $\begin{array}{l}6 \text { ventral (L5 to L7), } \\
\text { two of them split }\end{array}$ & No wasting \\
\hline \multirow[t]{2}{*}{1972} & B40 & 13 & \multirow{2}{*}{$\begin{array}{l}8 \text { ventral (L4 to L7), } \\
\text { two of them split } \\
2 \text { dorsal, } 3 \text { right lumbar } \\
\text { ventral, two of the } \\
\text { ventral split }\end{array}$} & No wasting \\
\hline & B44 & 25 & & $\begin{array}{l}\text { No wasting at } 15 \text { months. Wasting on right side in L5 } \\
\text { distribution at } 23 \text { months. Severe kyphosis with } \\
\text { rotation of L5 book. All roots and strands (including L5) } \\
\text { excitable at } 25 \text { months }\end{array}$ \\
\hline \multirow[t]{2}{*}{1974} & B57 & 30 & \multirow{2}{*}{$\begin{array}{l}6 \text { ventral (L6 and L7 one } \\
\text { side, S1 and S2 both sides) } \\
8 \text { ventral (L6, L7, S1, S2) } \\
1 \text { dorsal, } 6 \text { ventral (L6 and } \\
\text { L7 one side, S1 and S2 both } \\
\text { sides) }\end{array}$} & No wasting, despite severe kyphosis \\
\hline & $\begin{array}{l}\text { B58 } \\
\text { B64 }\end{array}$ & $\begin{array}{l}32 \text { (alive) } \\
14\end{array}$ & & $\begin{array}{l}\text { No wasting } \\
S 1 \text { and } S 2 \text { roots were inexcitable at } 1 \text { month, but they } \\
\text { regenerated. No wasting seen, the muscles innervated } \\
\text { by } S 1 \text { and } S 2 \text { being poorly visible }\end{array}$ \\
\hline \multirow[t]{2}{*}{1975} & B72 & 20 (alive) & \multirow{2}{*}{$\begin{array}{l}10 \text { ventral (L5 to S2), six } \\
\text { of them split } \\
10 \text { ventral (L5 to S2) }\end{array}$} & No wasting \\
\hline & B76 & 19 (alive) & & $\begin{array}{l}\text { The only wasting was that attributable to the intentional } \\
\text { electrolytic destruction of the right } \mathrm{L} 7 \text { ventral root; } \\
\text { and from this there has been full recovery }\end{array}$ \\
\hline
\end{tabular}


all human anterior nerve roots contain unmyelinated fibres, and of Floyd et al. (1976) that ventral roots in the cat contain fibres responding to peripheral stimulation, have revived old controversies about whether the Bell-Magendie law is true. The aspect of its truth or falsity that is of practical importance for the application of sacral anterior root stimulators to man is whether sacral anterior nerve roots contain pain fibres, and if so how they compare in diameter (and therefore in electrical threshold) with the somatic $\alpha$ motor nerve fibres and the preganglionic parasympathetic fibres of the same roots. To answer this question (as well as to avoid cruelty to animals), each of the seven baboons into which multivibrators were implanted for stimulating sacral ventral roots was carefully watched during the period of recovery from anaesthesia to see whether, when the multivibrator fired, there was any indication that the animal was suffering pain. If there had been, it would have been immediately re-anaesthetised and the multivibrator either switched off or removed. But there was no indication of pain in any case. The most informative animals are B55, B60, and $\mathrm{B} 85$, which were neurologically intact (in contrast to B53, which was paraplegic), and received stimulation powerful enough to give parasympathetic effects every two hours. In each of them, the first multivibrator firing in the conscious state caused only a slight startle reaction lasting for the first few seconds of the four minute stimulation, and the second and third firings still less. By the following day, firings caused no detectable alteration in whatever the animal was doing just before the firing; in particular, breathing was unaltered, and if the animal was chewing, the rhythm of chewing continued unchanged. Loud cries such as baboons utter when bitten by other baboons or when they are accidentally pinched by closing doors were never heard during stimulation of sacral ventral roots. 'Conversational' vocal exchanges with other baboons in the room were heard during stimulation about as of ten (per minute) as during non-stimulation. No baboon became noticeably thinner or fatter, or strikingly decreased or increased its food consumption, during its weeks of two hourly sacral root stimulation. All had glossy well-groomed coats at the beginning, and were still glossy and well-groomed at the end.

It seems, therefore, that baboon's S1 and S2 ventral nerve roots contain no pain fibres larger than or similar in size to the main group of preganglionic parasympathetic fibres. The observations do not exclude the possibility of unmyelinated pain fibres in these roots; the stimuli used would probably not excite any unmyelinated fibres.

\section{Conclusion}

In female baboons the present technique has been consistently successful in emptying the bladder, and mainly successful in holding back urine. In baboons of both sexes it has had few serious harmful effects. Of harmful effects that have occurred, by far the commonest was spinal deformity, and this is very unlikely to occur in man, where only the fifth lumbar vertebra and the first piece of the sacrum need have a laminectomy, and the articular processes can be spared on both sides. Trapping spinal nerve roots loosely in silicone rubber books does them no detectable harm in two years, and the successful regeneration of a root through a book after its intentional destruction in B76 suggests that even if harm is done unexpectedly, recovery is likely.

The most likely early application to human patients is in those cases of paraplegia where reflex micturition is unsatisfactory, either because it occurs much too frequently at very small bladder volume, or because it leaves a large residual vol ume. The technique requires that the anteriof horn cells of the sacral segments of the cord sur $\mathbb{D}$ vive, but does not require that any reflex mech anisms of the sacral cord be intact. In paraplegio patients with small irritable bladders it could b®e combined with posterior rhizotomy. Its use to $\overrightarrow{0}$ assist bladder emptying probably involves no risks beyond those inseparable from the surgical procedure of inserting the implant. Its use to hold back urine involves, at least theoretically, a risk of causing ureteric reflux and back-pressure damage to the kidneys. This risk can probably be made very small by a routine of sufficiently frequent emptying, but frequent intravenous pyelograms may be needed to check that the routine adopted is adequate.

Cables were made from May 1973 to June 1975 by Mr. J. D. Cooper, and since June 1975 by Miss J. Jackson to Mr. Cooper's design. Implantable multivibrators were designed and made by Mr. Cooper. I made the cables before May 1973, all the cauda equina implants and aortic occluding implants, and most of the implantable passive radio receivers. Mr. W. F. Piper made the moulds in which silicone rubber books were cast after October 1974. In most of the major surgery and some of the testing I was assisted by $\mathrm{Mr}$. (later Dr.) M. D. Craggs from January 1970 to March 1976, and by Dr. P. Gillan since April 1976. 


\section{References}

Alexander, S., and Rowan, D. (1968). Electrical control of urinary incontinence by radio implant. A report of 14 patients. British Journal of Surgery, 55, $358-364$.

Brädley, W. E., Wittmers, L. E., Chou, S. N., and French, L. A. (1962). Use of a radio transmitter receiver unit for the treatment of neurogenic bladder. A preliminary report. Journal of Neurosurgery, 19, 782-786.

Brindley, G. S. (1972). Electrode-arrays for making long-lasting electrical connexion to spinal roots. Journal of Physiology, 222, 135-136P.

Brindley, G. S. (1973). Emptying the bladder by stimulating sacral ventral roots. Journal of Physiology, 237, 15-16P.

Brindley, G. S. (1974). An implant for occluding arteries. Journal of Physiology, 246, 28-30P.

Brindley, G. S., Rushton, D. N., and Craggs, M. D. (1974). The pressure exerted by the external sphincter of the urethra when its motor fibres are stimulated electrically. British Journal of Urology, 46, 453-462.

Cajal, S. R. (1928). Degeneration and Regeneration of the Nervous System, Vol. 2, pp. 532-534. London: Oxford University Press.

Caldwell. K. P. S., Flack, F. C.. and Broad, A. F. (1965). Urinary incontinence following spinal injury treated by electronic implant. Lancet, 1, 846847.

Coggeshall, R. E., Applebaum, M. L., Fazen, M., Stubbs, T. B., and Sykes, M. T. (1975). Unmyelinated axons in human ventral roots. a possible explanation for the failure of dorsal rhizotomy to relieve pain. Brain, 98, 157-166.

Cotran, R., and Kass, E. (1958). Determination of the volume of residual urine in the bladder without catheterization. New England Journal of Medicine, 259, 337-339.

Edwards, L., and Malvern, J. (1972). Electronic control of incontinence. A critical review of the present situation. British Journal of Urology, 44, 467-472.

Elliott, T. R. (1907). The innervation of the bladder and urethra. Journal of Physiology, 35, 367-445.
Floyd, K., Koley, J., and Morrison, J. F. B. (1976). Afferent discharges in the sacral ventral roots of cats. Journal of Physiology, 259, 37-38P.

Grimes. J. H., and Nashold, B. S. (1974). Clinical application of electronic bladder stimulation in paraplegics. British Journal of Urology, 46, 653-657.

Hald, T., Meier, W., Khalili, A. Agrawal, G., Benton, J. G., and Kantrowitz, A. (1967). Clinical experience with a radio-linked bladder stimulator. Journal of Urology, 97, 73-78.

Halverstadt, D. B., and Parry, W. L. (1975). Electronic stimulation of the human bladder: nine years later. Journal of Urology, 113, 341-344.

Merrill. D. C. (1975). Clinical experience with the Mentor bladder stimulator. III: patients with urinary vesical hypotonia. Journal of Urology, 113, 335-337.

Merrill, D. C. (1976). Electric stimulation of the neurogenic bladder (detrusor). International Symposium on Electric Stimulation of the Neurogenic Bladder. Frankfurt 5-6 March 1976.

Nashold, B. S., Friedman, H., Glenn, J. F., Grimes, J. H., Barry, 'V. F., and Avery, R. (1972). Electromicturition in paraplegia. Archives of Surgery, 104, 195-202.

Nashold, B. S. (1976). Electric stimulation of the neurogenic bladder from the spinal cord. International Symposium on Electric Stimulation of the Neurogenic Bladder. Frankfurt 5-6 March 1976.

Riddle, P. R., Hill, D. W., and Wallace, D. M. (1969). Electronic techniques for the control of adult urinary incontinence. British Journal of Urology, 41, 205-210.

Scott, F. B., Queseda, E. M., Cardus, D., and Laskowski, T. (1965). Electronic bladder stimulation: dog and human experiments. Investigative Urology, 3, 231-243.

Stanton, S., and Edwards, L. E. (1973). Treatment of paediatric urinary incontinence by stimulator implant. British Journal of Urology, 45, 508-514.

Stenberg, C. C., Burnette, H. W., and Bunts, R. C. (1967). Electrical stimulation of human neurogenic bladders: experience with four patients. Journal of Urology, 97, 79-84. 